\title{
ENERGY CONSERVATION PROGRAMMES IN RUSSIA
}

\author{
Yuliia GERASIMENKO ${ }^{1}$ \\ ${ }^{1}$ Plekhanov Russian University of Economics, Russian Federation \\ u.v.usacheva@yandex.ru
}

\begin{abstract}
This article is devoted to the problem of state management in the sphere of energy-conservation in the building sector. This problem is vital to ensure the energy and environmental security of each country. That is why the concept of the article seems to be very scientifically important. The article presents the results of scientific analysis of the creation incentives for the development of energy-efficient building. The existent management approaches and a role of program-target method of management in Russia have been analysed. Some new measures of energy-saving innovation implementation are presented. The disadvantages of current energy-saving programme have been revealed, and the concept of its improvement has been suggested.
\end{abstract}

Keywords: Complex approach, Energy conservation program, process approach, system approach.

\section{INTRODUCTION}

Since the end of the 20th century, the path of innovative development of the economy has been chosen in Russia. Among the new and more advanced technologies, energy-saving innovations always had a special place. A programtarget method of management was approved to improve the energy efficiency of the domestic economy. So far, however, these measures have not given the desired effect - energy efficient building construction has not become mass, innovation activity is still related to rare investments in the construction materials industry.

\section{MANAGEMENT METHODS AND PROCEDURES}

The energy intensity of Russia's GDP is presented in Fig. 1. Some scientists believe (and not without reason) that it is necessary to develop and implement additional measures to reduce energy consumption in some sectors of the economy. One of the most energy-intensive areas is construction, so in this article the program-target method of management will be examined in the urban sector.

In order to identify the causes of ineffectiveness of the program-target method of management of energy-saving in Russia, it is necessary to examine the main approaches to management. Management was developed in stages, the last of which is informational (1960 - present) characterised by the development of theories, using computer technologies to include in the management theory mathematical analysis and subjective decisions of managers (expert evaluation 
method). At the same time, a system approach was presented, the main idea of which is that any action is not undertaken in isolation from the others. Every decision has consequences for the whole system. This approach provides the possibility of studying a large number of alternatives, the analysis of the constraints and consequences of decisions.

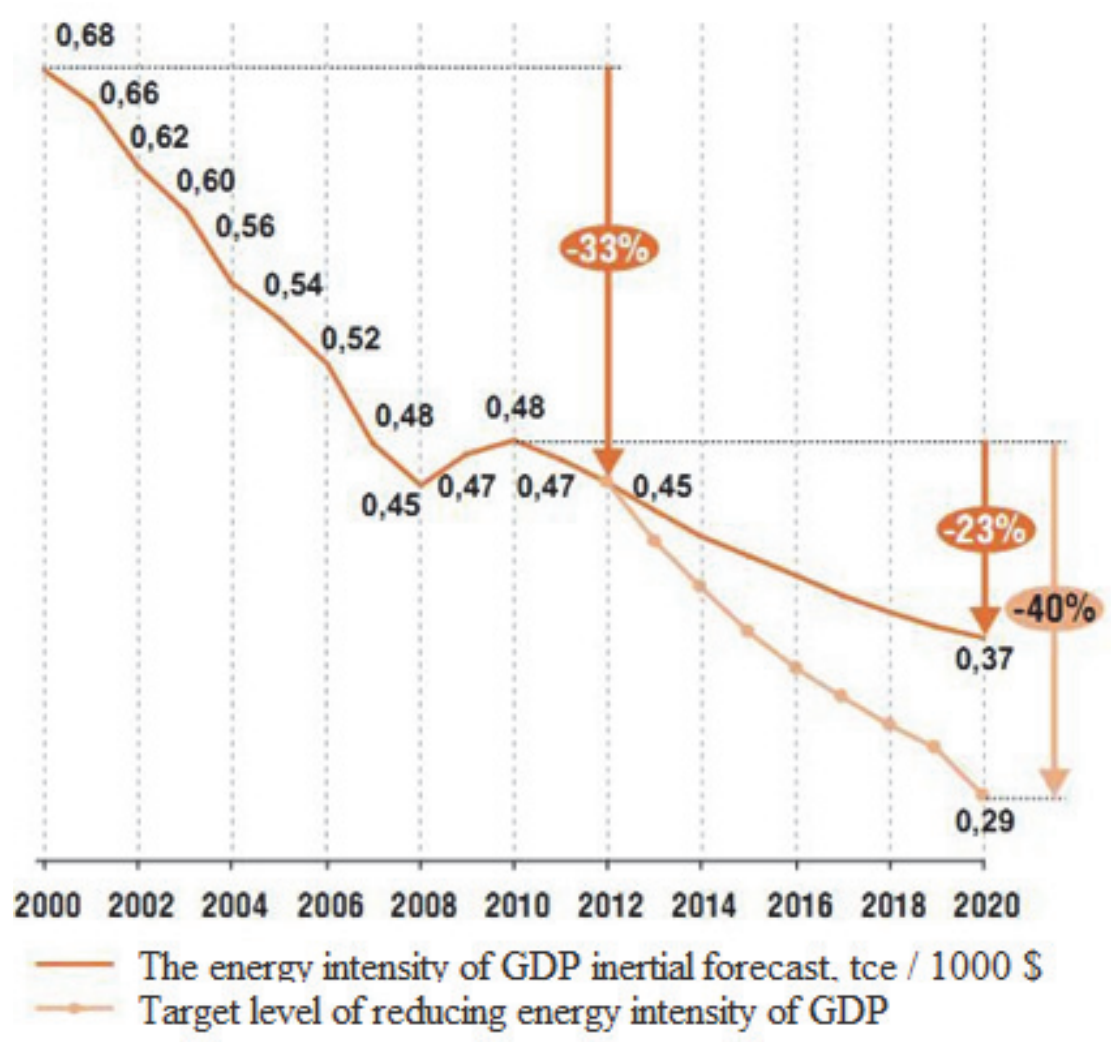

Fig. 1. The energy intensity of Russia's GDP, 2000-2020 (Bogdanov, 2015).

When considering the system approach as a method of management, it is necessary to take into account the fact that the object of study is always multifaceted and requires a comprehensive, complex approach; therefore, the study should include specialists in various fields. Comprehensiveness in a comprehensive approach expresses private demand, and in the system approach it represents one of the methodological principles. Thus, a complex approach develops strategy and tactics, and system alone - methodology and methods (Ansoff, 2007). In this case, there are a mutual enrichment complex and system approaches. A system approach is characterised by formality, unlike a complex approach. A complex approach is used not so much for considering objects from the standpoint of integrity, but rather for the comprehensive consideration of the investigated object.

A process approach plays a special role in the modern theory of management. The analysis has shown that the process approach considers management as a continuous series of interrelated managerial functions, i.e. planning, organisation, motivation, control, and linking processes - communication and decision-making 
(Mescon, Albert, and Khedouri, 2007). This approach creates confusion to this day. A. Fayol, in the framework of classical (administrative) school of management (in the 1920s), proposed for the first time considering the main functions of management as a process. Today, ISO 9001 standard "The Quality Management Systems. Requirements" has a leading role in the management of the organisation. Thus, it is noted that "an activity using resources and managed in order to transform inputs into outputs can be considered as a process" (ISO, 2008).

The main approaches to management, system, complex and process in combination allow making a realistic evaluation of the control object and selecting methods of achieving the set goals. Table 1 describes the purpose and features of each of these management approaches.

These approaches are not mutually exclusive and work together to identify the most effective management methods. As mentioned above, the main method of pressing strategic issues in Russia, including problems of energy efficiency in the construction industry, is government programming. The history of programmes to improve the energy efficiency of the Russian economy originated in 1999. Government programmes are used, including state and subroutine ones (in recent years, the issue of energy efficiency in the economy has the status of a state as a wide problem).

Table 1. System, Process, and Complex Approaches

\begin{tabular}{|l|l|l|}
\hline $\begin{array}{c}\text { The name of the } \\
\text { approach }\end{array}$ & \multicolumn{1}{|c|}{$\begin{array}{c}\text { The purpose of the } \\
\text { approach }\end{array}$} & \multicolumn{1}{|c|}{ Characteristics of the approach } \\
\hline Process approach & $\begin{array}{l}\text { View of the control } \\
\text { object and content of } \\
\text { the management }\end{array}$ & $\begin{array}{l}\text { Object of management - a process that } \\
\text { operates with the help of management } \\
\text { Management is a process consisting of steps: } \\
\text { planning, organisation, motivation, and } \\
\text { control }\end{array}$ \\
\hline Complex approach & Management strategy & $\begin{array}{l}\text { Comprehensive consideration of the issue } \\
\text { (allied sciences) }\end{array}$ \\
\hline System approach & Management methods & The linkage within the system \\
\hline
\end{tabular}

The state programmes are formed on the principle of full coverage of all spheres of socio-economic development of the country based on long-term goals and indicators of their achievement. For each state programme, a list of measurable final results is established. To achieve the objectives of state regular measures (title, enforcement and control), financial measures (budget, tax, customs, property, credit, debt and monetary) are used.

\section{ENERGY-SAVING PROGRAMMES}

Today, there is a complex of legal documents in the energy-saving sphere. The main purpose of them is to reduce energy intensity of GRP (gross regional product). State energy-saving management bases on the following principles: 
1. Efficient and rational use of energy resources;

2. Support and stimulation of energy saving and energy efficiency;

3. A systematic and comprehensive event on energy saving and increase of power efficiency;

4. Planning of energy saving and energy efficiency;

5. Use of energy resources based on the resource, technological, environmental and social conditions.

State regulation in the field of energy saving and increasing energy efficiency includes the establishment of:

1. The requirements for sales of certain products, the functional purpose of which involves the use of energy resources;

2. Prohibitions or restrictions of production and turnover of products with low energy efficiency, subject to the availability of the turnover or turnover of a similar purpose of use of products with high energy efficiency, in quantities that meet the demand of consumers;

3. Obligations on account of used power resources;

4. The energy efficiency requirements of buildings, structures, constructions;

5. Responsibilities of the energy audit;

6. The requirements for the energy audit and its results;

7. Duties of events on energy saving and increase of power efficiency concerning the general property of proprietors of premises in an apartment house;

8. Energy efficiency requirements for goods, works and services for state or municipal needs;

9. The requirements for regional and municipal programmes in the field of energy saving and increase of power efficiency;

10. Requirements for programmes in the field of energy saving and energy efficiency with participation of the state or the municipality and organisations engaged in regulated activities;

11. Basic functioning of the state information system in the field of energy saving and energy efficiency;

12. Duties of disseminating information in the field of energy saving and energy efficiency;

13. Responsibilities of the implementation of information programmes and educational programmes in the field of energy saving and energy efficiency.

This is a general view of the order of development of state programmes in Russia at the moment. However, a number of unresolved social problems and low efficiency of many programmes adopted to address complex socio-economic problems lead to the existence of problems of state regulation, and not only for our country.

Improving the efficiency of state regulation of social processes since the mid 90-ies has become the subject of attention of international organisations. 
A strategy of synergistic election was recommended for developing government programs during the 12th meeting of experts on the United Nations Program in public administration and finance. This is the strategy of complex (and system) of long-term planning of social development (50 years). International experts urge people to think in terms of "major strategies and large undertakings". This transition is a new moment for Western management. However, a value approach, which involves consideration of moral aspects and categories, is understandable to any member of the society. It turned out that the underlying individual enrichment motivated by the market society creates a significant deficit of collective moral inspiration needed to solve major national problems. The main characteristics of synergistic strategies, according to UNO experts, are the 16 principles that need to guide the formulation of government programmes. Here are some of them (The $12^{\text {th }}$ Conference of Experts of UNO on the Point of State Management, 1995):

- Conceptual thinking strategic perspective with a focus on realistic goals.

- A sufficient degree of understanding of global historical processes.

- A thorough self-analysis in terms of strategic instability.

- The long-term perspective.

- A systemic approach.

- Value approach.

- The permanent readiness to generalise the experience gained during the implementation of the programme.

It should be noted that for Russia the planning and formulation of national tasks in particular is nothing new and was used extensively in the Soviet period.

These are the main approaches to public administration, recognised perspective on a global level. Obviously, currently developing programmes in Russia is far from an ideal synergistic strategy. The objective is to reduce energy intensity of gross domestic product - it is the economic problem, not the national one. In this regard, the promotion of energy saving, which is part of any energy saving programme, according to a process approach, cannot have a mass character and a non-commercial basis, since the main purpose of the programme does not contain the moral and psychological components that are understandable to every member of society.

These conceptual disadvantages are inherent to main energy-saving programmes of Russia in general and Moscow in particular. A critical analysis of the current state programme, guided by the above-described management approaches and worldviews, allows highlighting the main disadvantages:

- main goal of the programme is not structured according to some criterion that does not allow a system approach to the planning of programme activities;

- motivating system includes only one method (the differentiation of tariffs for energy resources), which does not reflect the holistic approach a complex review of the problem; 
- system for monitoring the effectiveness of interventions is not worked out properly and is reduced to the accumulation of information without any systematisation and analysis;

- organisation of the programme is not long-term oriented and does not offer a mechanism to revise the targets of the programme for future periods.

It is important to note that all Russian programmes are regularly corrected. And these disadvantages are considered to be eliminated.

Therefore, there are new measures, which coordinate all urban sector programmes in terms of creation of objects of capital construction, accumulate the results, and identify priorities for urban development in the future:

1. "Development of economic mechanisms for the implementation of urban policy and stimulation of investment activity in the field of urban planning" provides state planning and programming, preliminary risk assessment, implementation of large urban development projects, regulation of investment activity that can be done through public investment, subsidies, incentives (including tax), lending and stimulating the innovative process of reforming of the enterprises of a building complex for the purpose of increase of their investment attractiveness (process approach to management);

2. "Scientific, technical and methodological developments in the field of application of new organisational, economic and managerial solutions, materials, technologies and equipment" include the analysis, systematisation and implementation of scientific and methodological developments in order to ensure and implement innovative development of the construction complex (the complex approach as a comprehensive scientific study of the problem);

3. "Implementation of advanced energy efficiency and other innovative technologies in construction" suggests a system approach to the problem of energy-saving by combination of the following measures:

- methods of analysis and estimation of innovative technology efficiency;

- measures to stimulate the introduction of innovative technologies;

- economic feasibility study on the introduction of innovative developments at specific objects.

In general, the process approach can be applied to describe the mechanism of modernisation of energy efficiency programmes in the construction industry. Additional mechanisms would form a cycle of phases of the process approach, as shown in Fig. 2.

This mechanism includes such decisions as energy efficiency promotion, mathematical model of the stimulation system, as well as methods of control and analysis of the effectiveness of the programme (Usacheva and Dmitriev, 2011). The authors do not claim that the cycle shown in Fig. 2 will provide the solution to the problem of energy saving in the construction industry. However, this example clearly demonstrates that a complex, process and system management approaches together should be applied, as confirmed by the latest researches. 


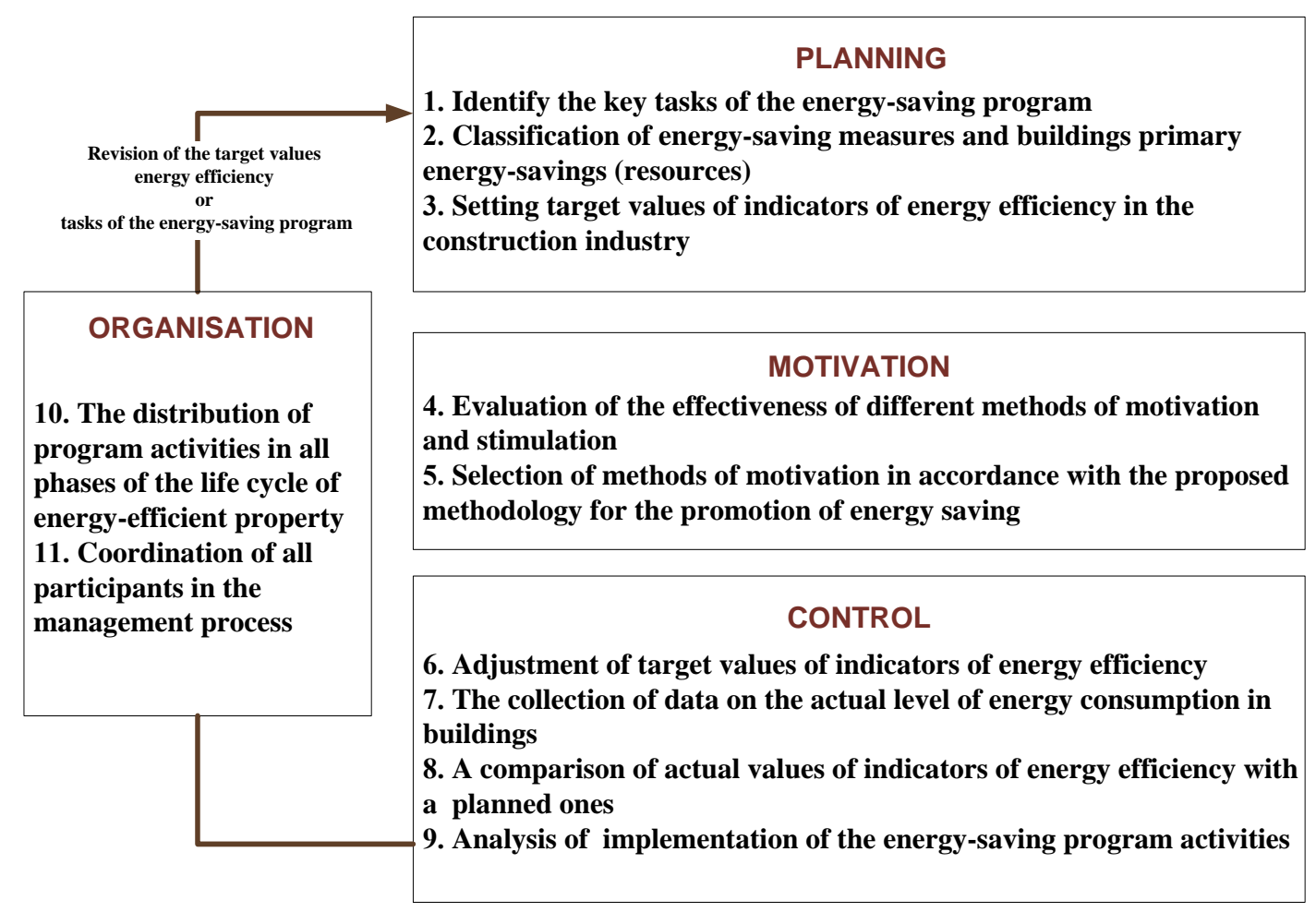

Fig. 2. The implementation of the process approach

to the energy-saving programme.

\section{MOTIVATION METHODS}

Special attention in the formation of programmes on reduction of energy consumption in most countries of the world is given to motivation of energysaving innovations. Methods of motivation, in turn, are proposed to distinguish by the method of influence on the object:

1. The original motivation - possessed by an object due to the availability of interest in performing the required actions. However, such motivation is usually not enough to perform the required actions.

2. Direct motivation - influence directly formed on the interest object. Direct motivation includes methods, involving direct cash payments in the event of certain actions by the object of motivation.

3. Indirect motivation - impact indirectly on the interest object. These methods form the conditions for the creation of interest and do not involve direct cash payments.

Thus, both direct and indirect methods of motivation can be tangible (economic) and intangible.

It is well known that the existing method of motivation for energy saving of an investor (a developer) is the so-called "green standard". In 1990, for the first time in the UK "green building" standard BREEAM was promulgated. In 2002, the USGBC (the U.S. green buildings) issued a LEED (Leadership in Energy and Environmental Design), which is a program evaluation of the building and assigns 
rating points, most of which relate to energy conservation. There is a similar system of voluntary certification of real estate in Russia - "Green Standards". In this system, there is a special section dedicated to the energy conservation design of buildings and completed projects. These ratios are not binding and may affect the energy intensity of the industry only in terms of the overall focus on the energy efficiency of a building complex in general and all its participants. For example, tax holidays for a period of 5-7 years are used for the activities of the innovation centre in Skolkovo, or substituting from the budget of part of interest on commercial loans taken for the development of innovations (BREEAM, 2009).

There are some mechanisms to encourage energy efficient construction in Moscow today. Owners of energy efficient buildings have tax benefits:

1. Within three years from the date of registration of the property, with high energy efficiency or having a high energy efficiency class - such property is not included in the tax base for a property tax.

2. The same categories of fixed assets establish the right of a taxpayer to apply higher depreciation coefficient of 2 to the objects with high efficiency.

For comparison, Hungary has adopted a programme of energy saving measures and energy efficiency, mobilising investments worth 200 billion HUF (750 million EUR). Moreover, they are providing grants for the implementation of energy efficiency investments in private homes. The grant is $30 \%$ of the total investment in the range of 200 thousand HUF (about 765 EUR) per household. The average payback period is less than 10 years, and the effectiveness of such grants, according to our calculations, accounted for about 5 million joules per 1 Euro invested in motivation means. However, the Hungarian experience shows that grants for modernisation of district heating systems lead to greater energy savings than grants in respect of projects related to energy demand. Budgetary efficiency index of such incentives for energy conservation is 4.01 (Meszáros, 2002), which means a fourfold effect on the investment in the motivation tools.

The Netherlands also has a scheme of "green investments" ("green funds"), which provides loans with low $2 \%$ interest rates for the implementation of environmentally friendly projects at a low rate. The population had invested over 2 billion NLG (Dutch guilders) ( 0.9 billion EUR) in green funds. About 500 projects were classified as "green", including seven of them were in the field of biomass energy. The total amount of "green" investments in these projects accounted for 58 million NLG (26.4 million EUR) (Energy-saving investments, 2006). It is easy to calculate that the budget efficiency investment in the fiscal stimulus is 2.11 per unit of invested funds.

However, as shown by the analysis of domestic experience, promoting energy conservation; existing measures have not had the desired effect. Some motivational mechanisms, common in foreign countries, are also present in the Russian practice, however, have individual character (for example, benefits provided to the innovation centre in Skolkovo). In our view, the promotion of energy-saving technologies requires a comprehensive approach, considering the economic interests of all participants, investment and construction activities, including: the interests of the customer, investor, research organisations, 
manufacturers of energy-saving materials and constructions, designers, contractors, buyers with regard to economic rationality, the budget allocation.

In this connection, it is necessary to create incentives for the development of energy-efficient housing aimed at the motivation for the initial and final stages of the life cycle of energy-efficient buildings. To perform the tasks, priority is represented by two methods of motivation:

1. The decrease in the rate of income tax for companies that invest in energy-efficient construction;

2. Preferential mortgage loans to buyers of apartments in the house of high and increased energy efficiency.

\section{RESULTS}

The successful functioning of these incentives will have an impact on the participants of the investment process from two sides, creating both the demand and supply. In this case, there is no need of financing motivation "intermediate links", such as manufacturers of energy efficient construction materials, or passive house designer - the impact on the supply and demand will create favourable conditions for business development in an energy efficient way without budgetary support. This incentive system eliminates the inefficient expenditure of budgetary funds, encouraging the production of goods for which there is no demand or the design of buildings, construction of which has not been funded.

\section{CONCLUSION}

There is a need to restructure the use of government programming in the solution of strategic tasks of economics of Russia. The research institutions and executive specialists of state authorities already participate in this work, successfully applying process, complex and system approaches to target programming, considering foreign experience in this sphere. All the aforementioned gives us a reason to believe that soon the program-target method in Russia will begin to function more effectively, and rightly become the main tool for solving economic and social problems of the country.

\section{ACKNOWLEDGMENT}

The present research has been supported by the Russian Humanitarian Scientific Fund (RGNF) [15-32-01383].

\section{REFERENCES}

Ansoff, H. I. (2007). Strategic Management. Palgrave Macmillan, 114, Retried from http://dx.doi.org/10.1057/9780230590601.

Bogdanov, A. B. (2015). Reducing the energy intensity of Russia to the competence of energy regulators not applicable. Portal-Energo, an electronic journal website: http://portal-energo.ru/ articles/details/id/782. 
BREEAM Europe Commercial (2009). Assessor Manual, SD 5066A Issue 1.0. BRE Global. Retried from http://www.breeam.org.

Energy-saving investments (2006). The elimination of the barriers/Energy Charter Secretariat. Belgium, Boulevard de la Woluwe, 56 / B-1200 Brussels, Dépôt légal D/2004/7850/4.

ISO 9001:2008 Quality management systems. Requirement (2008), ar. IV.

Making the Position of Governments in the Field of Politics Stronger (1995). The $12^{\text {th }}$ Conference of Experts of UNO on the Point of State Management, 11-12.

Mescon, M. H., Albert, M., Khedouri, F. (2007) Midlan International,Third Edition, HARPER \& ROW, PUBLISHERS, NEW YORK, Cambridge, Philadelphia, San Francisco, Washington, London, Mexico Oty, Sao Paulo, Singapore, Sydney, p. 48.

Meszáros, G. S., Haidegger, K. (2002). Plan, Quick analysis on the results of the Energy Efficiency Plan. Energy Centre Non-profit. Budapest.

Usacheva, Y.V., Dmitriev, A. N. (2011). The mechanism of state incentives for energy conservation in construction. STROYMATERIALY. No. 12, 47-50.

\section{AUTHORS' SHORT BIOGRAPHY}

Gerasimenko Yuliia Vladislavovna received the degree of Candidate of Economic Sciences in 2013 from the Department of Management of Projects and Programs, Plekhanov Russian University of Economics. The research area is energy efficiency, engineering, public administration, economic evaluation of projects.

Since 2010, she has been working at the Scientific Research and Project Institute of Typology and Experimental Design (Head of the Department of Energy Efficiency and Energy Audit), combining the basic work with the teaching of the course "Operations Management" at the Russian Plekhanov University of Economics (Senior Teacher). She has 19 publications, including papers elaborated in the framework of participation in the grant by the Russian Humanitarian Scientific Fund (RGNF) No. 15-32-01383, No. 12-02-00178.

She is a co-author of the draft of national standards for designing energy efficient buildings of educational institutions. 